\title{
Effects of face masks on performance and cardiorespiratory response in well-trained athletes
}

\author{
Florian Egger ${ }^{1,2}$ (D) Dominic Blumenauer ${ }^{1} \cdot$ Patrick Fischer $^{1} \cdot$ Andreas Venhorst $^{2} \cdot$ Saarraaken Kulenthiran $^{1}$. \\ Yvonne Bewarder ${ }^{1} \cdot$ Angela Zimmer $^{1} \cdot$ Michael Böhm $^{1} \cdot$ Tim Meyer $^{2} \cdot$ Felix Mahfoud $^{1}$
}

Received: 2 May 2021 / Accepted: 19 May 2021 / Published online: 6 June 2021

(c) The Author(s) 2021

\begin{abstract}
Background During the COVID-19 pandemic, compulsory masks became an integral part of outdoor sports such as jogging in crowded areas (e.g. city parks) as well as indoor sports in gyms and sports centers. This study, therefore, aimed to investigate the effects of medical face masks on performance and cardiorespiratory parameters in athletes.

Methods In a randomized, cross-over design, 16 well-trained athletes (age $27 \pm 7$ years, peak oxygen consumption $56.2 \pm 5.6 \mathrm{ml} \mathrm{kg}^{-1} \mathrm{~min}^{-1}$, maximum performance $5.1 \pm 0.5 \mathrm{Watt} \mathrm{kg}^{-1}$ ) underwent three stepwise incremental exercise tests to exhaustion without mask (NM), with surgical mask (SM) and FFP2 mask (FFP2). Cardiorespiratory and metabolic responses were monitored by spiroergometry and blood lactate (BLa) testing throughout the tests.

Results There was a large effect of masks on performance with a significant reduction of maximum performance with SM $(355 \pm 41$ Watt $)$ and FFP2 $(364 \pm 43$ Watt $)$ compared to NM $(377 \pm 40$ Watt $)$, respectively $\left(p<0.001 ; \eta p^{2}=0.50\right)$. A large interaction effect with a reduction of both oxygen consumption $\left(p<0.001 ; \eta p^{2}=0.34\right)$ and minute ventilation $(p<0.001$; $\left.\eta p^{2}=0.39\right)$ was observed. At the termination of the test with SM 11 of 16 subjects reported acute dyspnea from the suction of the wet and deformed mask. No difference in performance was observed at the individual anaerobic threshold $(p=0.90)$. Conclusion Both SM and to a lesser extent FFP2 were associated with reduced maximum performance, minute ventilation, and oxygen consumption. For strenuous anaerobic exercise, an FFP2 mask may be preferred over an SM.
\end{abstract}

Keywords Masks $\cdot$ Cardiopulmonary exercise test $\cdot$ Athletes

\section{Introduction}

Face masks have been shown to actively contain transmission of SARS-CoV-2 [1-3]. During the COVID-19 pandemic, public authorities in various countries made it mandatory to wear face masks in indoor and outdoor public places. Additionally, compulsory masks became an integral part of sport including gyms and sports centers. However, uniform recommendations for athletes to wear a face mask during exercise do not yet exist. According to the United States Center for Disease Control and Prevention

Florian Egger

florian.egger@uni-saarland.de

1 Department of Internal Medicine, Saarland University Hospital, Homburg, Saar, Germany

2 Institute of Sports and Preventive Medicine, Saarland University, Campus, Building B8 2, 66123 Saarbrücken, Germany guidelines, masks are especially recommended especially for indoor sports such as basketball, but also for low- and high-intensity outdoor training whenever feasible [4]. The World Health Organization has published less precise recommendations and advised against wearing masks during strenuous exercise [5]. Exercising at higher intensities might lead to increased moisture retention resulting in the deformation of less rigid masks [6]. A wet mask is harder to breathe through and filters less efficiently and it has therefore been recommended to change masks regularly when exercising [4]. To date, few studies investigated the effect of face masks on physical performance in healthy (untrained) individuals [7-10].

Data on the effects of face masks during strenuous exercise are scarce, with a single study focusing on steady-state exercise [10]. To the best of our knowledge, no study has yet examined the effects of face masks on the individual anaerobic threshold in athletes, an intensity marker commonly used for training prescriptions in endurance sports $[11,12]$. This 
study, therefore, aimed to investigate the effects of medical face masks on both maximal and submaximal performance in well-trained athletes regularly participating in training and competition, to provide evidence for training recommendations including preventive aspects as potential side effects of masks.

\section{Methods}

\section{General design}

In a randomized, cross-over design, subjects underwent three stepwise incremental exercise tests: (i) one without mask (NM), (ii) with a surgical mask (SM) and (iii) with a FFP2 mask (FFP2). All tests were performed at the same time of day, at least $48 \mathrm{~h}$ apart from each other, and completed within two weeks. During the test period, subjects were instructed to continue their normal training routine but to abstain from strenuous and prolonged ( $>30 \mathrm{~min}$ ) exercise $24 \mathrm{~h}$ prior to the assessment and to maintain their usual carbohydrate-rich diet. Prior to each test, subjects received standardized questions regarding self-evaluation of physical condition, hydration status, and compliance to dietary and exercise restrictions. All tests were carried out under standardised laboratory conditions with measurement of relative humidity and ambient temperature (Sonomo thermo- and hygrometer, Wuhan, China; measurement interval $10 \mathrm{~s}$ ).

\section{Subjects}

Sixteen well-trained, healthy male athletes ( 2 road cyclists, 8 mountain bikers, 6 triathletes; peal oxygen consumption $\left(V \mathrm{O}_{2 \text { peak }}\right) 56.2 \pm 5.6 \mathrm{ml} \mathrm{kg}^{-1} \mathrm{~min}^{-1}$, age $27 \pm 7$ years, BMI $22.5 \pm 1.8 \mathrm{~kg} \mathrm{~m}^{-2}$ ) volunteered to participate in this study. On their first visit to the laboratory, each subject underwent a medical check-up consisting of a physical examination, history, 12-lead ECG, and resting office blood pressure measurement. Further investigations (blood count, wholebody plethysmography, echocardiography) were carried out only if medically indicated. Subjects were eligible if they met the following inclusion criteria: age 18-40 years, cycle training $\geq 6 \mathrm{~h}$ per week, individual anaerobic threshold (IAT) $>200$ Watt (W), maximum performance during a stepwise incremental cycle test of at least $4.6 \mathrm{~W} \mathrm{~kg}^{-1}$ (performance level 3) [13]. All subjects were fully informed about the experimental procedures and provided written informed consent prior to participation. The study was carried out in accordance with the declaration of Helsinki and approved by the local ethics committee (Ärztekammer des Saarlandes, Saarbrücken, Germany; approval number: 199/20).

\section{Incremental exercise test}

Subjects performed all trials with clipless pedals on their own bikes attached to an electromagnetically bicycle ergometer (Cyclus 2, RBM elektronik-automation GmbH, Leipzig, Germany). Individual seat and handlebar position was maintained throughout. Subjects started cycling at $100 \mathrm{~W}$ or $150 \mathrm{~W}$ and workload was increased every 3 min by $50 \mathrm{~W}$ until exhaustion. After each step subjects were asked to rate their rate of perceived exertion (RPE) on a 10-point scale (Borg CR10) [14]. Arterialized capillary blood was obtained from the hyperemised earlobe for analyzing blood lactate (BLa; enzymatic-amperometric method, Greiner, Flacht, Germany) at rest, at the end of each step, at cessation and 1, 3, 5, 7 and 10 min post-exercise. Based on a performance curve, IAT was determined using the methods described by Stegmann et al. [15]. Tests were terminated when subjects signalized maximum exhaustion or were unable to maintain a pedaling cadence of 50 revolutions per minute $(\mathrm{rpm})$ for more than $10 \mathrm{~s}$. Objective criteria for exhaustion (i.e. heart rate $(\mathrm{HR})_{\max }$ [208 - 0.7 $\times$ age]; $\mathrm{BLa}_{\max }>9 \mathrm{mmol}^{-1}$; respiratory quotient $>1.1$ ) were applied according to the current literature $[16,17]$. Gas exchange parameters were measured continuously with a MetaMax II metabolic test system (Cortex Biophysik, Leipzig, Germany; mixing chamber; sampling frequency $10 \mathrm{~s}$ ). Time courses of oxygen consumption $\left(V \mathrm{O}_{2}\right)$ and respiratory minute ventilation (VE) were calculated using the mean of 3 contiguous values at the end of each step and at exhaustion. Heart rate was derived from continuous 12-lead ECG recordings. Blood pressure was measured manually at rest, at the end of each step, and 1, 3, 5 min post-exercise.

\section{Fitting of the face masks}

FFP2 protective face masks (Shezhen Source Innovation Technologies Co. Ltd., Guangdong, China) and surgical masks (Quanzhou Nanfang Sanitary Products Co. Ltd., Quanzhou City, China) were used for this study. A loose spirometry mask (not connected to the volume sensor) was placed over the respective face mask and fixed and tightened with head straps. Subsequently, the subject was asked to close the valve of the spirometry mask with the heel of his hand and to exhale firmly against it to check for leaks. This maneuver was repeated under the careful supervision of the examiner until no acoustic, visual, and sensory indications of leakage were detectable. By selecting 3 different mask sizes (small, medium, large) an adequate seal of the mask could always be achieved before attaching the volume sensor and starting the measurement. 


\section{Outcome measures}

Maximal performance $\left(P_{\max }\right)$ and submaximal performance at IAT $\left(P_{\text {IAT }}\right)$ were the main outcome measures in this study. Secondary outcome measures included HR, blood pressure, $\mathrm{VE}, V \mathrm{O}_{2}$, carbon dioxide production $\left(V \mathrm{CO}_{2}\right)$, BLa, and RPE.

\section{Statistical analysis}

Since there were very limited data published to establish baseline assumptions, no formal sample size estimation was performed. Subjects were randomly assigned to the sequence of exercise with NM, SM or FFP2. Statistical analyses were performed using GraphPad (version 9.0).

Data were screened for outliers, in one case multiple imputation procedure was applied. Because all dependent variables were normally distributed (Shapiro-Wilk test), parametric tests were applied, and data are presented as mean \pm standard deviation. Differences between conditions were tested for significance using one-factorial ANOVA. Differences in time courses of $\mathrm{HR}, \mathrm{BLa}, \mathrm{VO}_{2}$, and $\mathrm{VE}$ between conditions during incremental exercise tests were compared using two-way repeated-measures ANOVA. Greenhouse-Geisser epsilon adjustment was made when sphericity was violated. When the difference between means was significant, post-hoc comparisons were performed by means of the Tukey test. Effect sizes were calculated as partial eta-squared $\left(\eta p^{2}\right)$ and interpreted as small $(0.01)$, medium (0.06), or large (0.14) [18].The significance level for the alpha error was set at $p<0.05$.

\section{Results}

All 16 subjects completed the study and the three incremental exercise tests were performed within $9 \pm 4$ days (range 5-14 days) between June 2020 and January 2021. There was no difference in ambient temperature (NM: $21.6 \pm 2.6^{\circ} \mathrm{C}$; SM: $20.3 \pm 3.6{ }^{\circ} \mathrm{C}$; FFP2: $\left.21.7 \pm 2.1{ }^{\circ} \mathrm{C} ; p=0.34\right)$ and relative humidity (NM: $38.4 \pm 5.4 \%$; SM: $37.9 \pm 6.0 \%$; FFP2: $40.3 \pm 4.9 \% ; p=0.21$ ) during the incremental exercise tests. For each condition, at least one of the objective criteria for exhaustion was exceeded.

\section{Performance}

$P_{\max }$ differed significantly between NM $(377 \pm 40 \mathrm{~W})$, SM $(355 \pm 41 \mathrm{~W})$ and FFP2 $(364 \pm 43 \mathrm{~W})$, respectively $\left(F_{2,30}=18.3 ; p<0.001 ; \eta p^{2}=0.5\right)$. Compared with NM, $P_{\max }$ was decreased by $21.3 \pm 15.1 \mathrm{~W}$ [ $95 \%$ confidence interval (CI) 11.5 to $31.1, p<0.001]$ and $12.4 \pm 13.2 \mathrm{~W}(95 \% \mathrm{CI}$ 3.9 to $21.0, p<0.01$ ) with SM and FFP2, respectively. The reduction of $P_{\max }$ compared with NM was $-5.6 \pm 4.1 \%$ (95\%
$\mathrm{CI}-3.5$ to $-7.8, p<0.001)$ and $-3.7 \pm 3.1 \%(95 \% \mathrm{CI}$ -2.2 to $-5.7, p<0.01$ ) with SM and FFP2, respectively. The difference of $8.8 \pm 14.0 \mathrm{~W}$ in $P_{\max }$ between SM and FFP2 did not reach statistical significance $(95 \%$ CI -18.0 to $0.3, p=0.06) . P_{\max }$ related to body weight was decreased by $-0.3 \pm 0.2 \mathrm{~W} \mathrm{~kg}^{-1}(95 \% \mathrm{CI}-0.4$ to $-0.2, p<0.001)$ and $-0.2 \pm 0.1 \mathrm{~W} \mathrm{~kg}^{-1}(95 \% \mathrm{CI}-0.3$ to $-0.1, p<0.001)$ with SM and FFP2 compared to NM, respectively (Fig. 1). No difference in $P_{\text {IAT }}$ was observed between conditions $\left(F_{1.7 ; 25.2}=0.07 ; p=0.90\right)$.

\section{Cardiocirculatory, respiratory and metabolic parameters}

Time courses of $\mathrm{HR}, \mathrm{VO}_{2}, \mathrm{VE}$ and $\mathrm{BLa}$ as a function of performance (percentage of peak power output) are illustrated in Fig. 2. HR did not differ between conditions at any scalar time point during the incremental cycling test $\left(F_{10,225}=1.0\right.$; $p=0.37)$. There was a large interaction effect for both $\mathrm{VO}_{2}$ $\left(F_{10,225}=11.8 ; p<0.001 ; \eta p^{2}=0.34\right)$ and $\operatorname{VE}\left(F_{10,225}=14.6\right.$; $\left.p<0.001 ; \eta p^{2}=0.39\right)$ between conditions over time showing decreases for both SM and FFP2 compared with NM at $40 \%, 60 \%, 80 \%$ and $100 \%$ of peak power output. The change in $\mathrm{VO}_{2 \text { peak }}$ was $-13.8 \pm 9.0 \mathrm{ml} \mathrm{kg} \mathrm{kin}^{-1}(95 \% \mathrm{CI}$ -19.6 to $-7.9, p<0.001)$ and $-11.1 \pm 5.9 \mathrm{ml} \mathrm{kg}^{-1} \mathrm{~min}^{-1}$ $(95 \% \mathrm{CI}-15.0$ to $-7.3, p<0.001)$ and the change in peak minute ventilation was $-64.7 \pm 33.01 \mathrm{~min}^{-1}(95 \% \mathrm{CI}-86.1$ to $-43.2, p<0.001)$ and $-46.9 \pm 22.51 \mathrm{~min}^{-1}(95 \% \mathrm{CI}$ -61.5 to $-32.3, p<0.001$ ) with SM and FFP2, respectively (Fig. 1).

Moreover, a large interaction effect for BLa between conditions and time of measurement $\left(F_{10,210}=5.5 ; p<0.001\right.$; $\left.\eta p^{2}=0.2\right)$ was present and post-hoc tests located a decrease in BLa concentration by $1.0 \mathrm{mmol} \mathrm{l}^{-1}$ at $80 \%$ (95\% CI 0.04 to $1.0, p=0.04$ ) and by $2.0 \mathrm{mmol}^{-1}$ at $100 \%$ of peak power output (95\% CI 0.5 to 3.5, $p=0.008$ ) between SM and NM, respectively (Fig. 2). With FFP2 the decrease of $\mathrm{BLa}_{\max }$ by $-0.8 \mathrm{mmol} \mathrm{l}^{-1}(95 \% \mathrm{CI}-1.9$ to $0.24, p=0.14$ ) was not significant (Fig. 1). The exercise-dependent responses of additional parameters such as blood pressure, HR recovery and $V \mathrm{CO}_{2}$ between conditions are presented in Table 1 .

\section{Subjective criteria for exhaustion}

Exercising without a mask was terminated by all subjects due to volitional exhaustion $(n=16)$. No difference between conditions was observed for RPE throughout the incremental cycling test $\left(F_{10,225}=0.4 ; p=0.93\right)$. At higher intensities with SM, all 16 subjects uniformly reported increasing wetting and deformation of the mask, which was also observed by the investigators when removing the spirometry mask post-exercise. Acute dyspnea due to suction of the mask led to abrupt exercise cessation in 11 of 
A

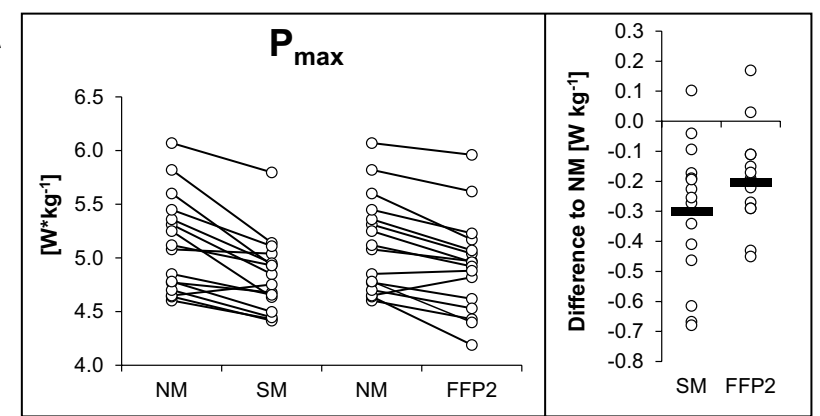

C

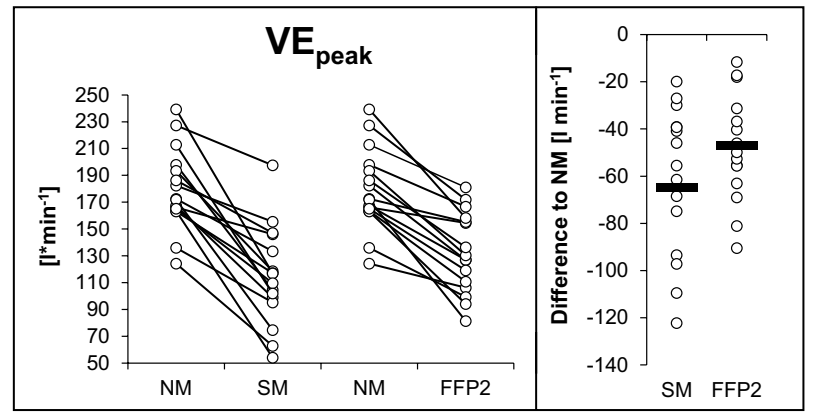

Fig. 1 Interindividual differences at exhaustion during the incremental exercise test $(n=16)$ without a mask $(\mathrm{NM})$, with a surgical mask (SM), and with FFP2-mask (FFP2). A maximum performance $\left(P_{\max }\right)$.
$\mathrm{B}$

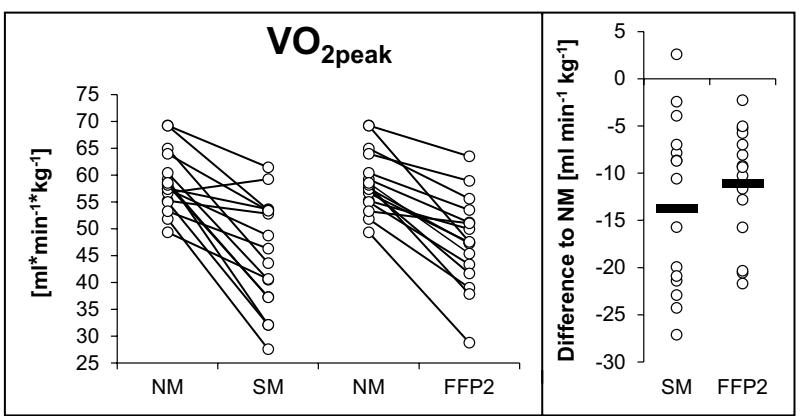

$\mathrm{D}$

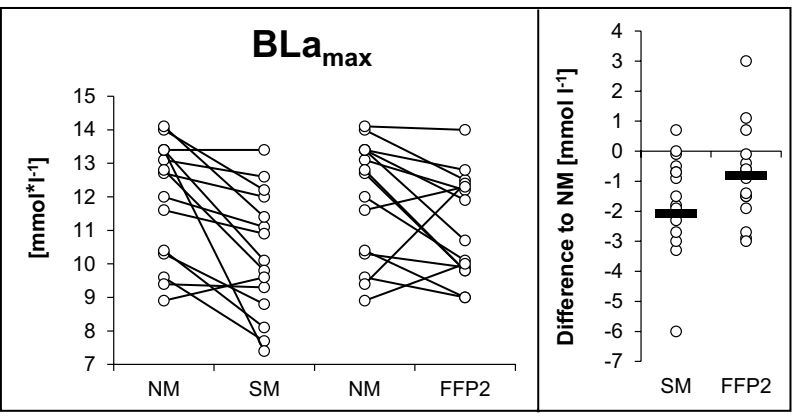

B peak oxygen consumption $\left(V \mathrm{O}_{2 \text { peak }}\right)$. C peak minute ventilation $\left(\mathrm{VE}_{\text {peak }}\right), \mathbf{D}$ maximum blood lactate concentration $\left(\mathrm{BLa}_{\max }\right)$. W Watt
A

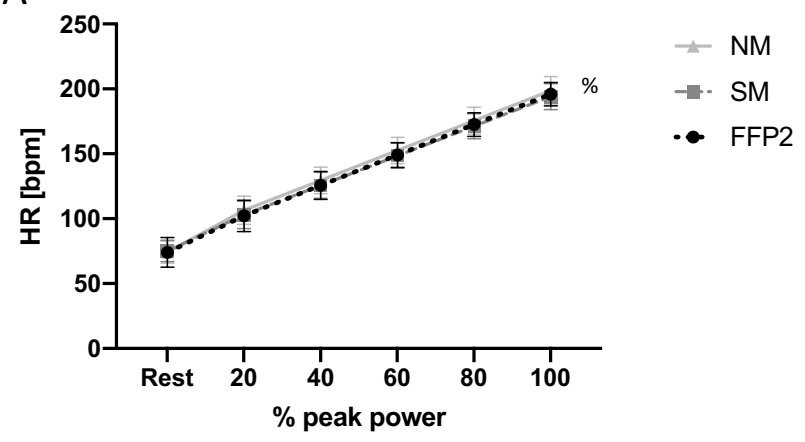

C

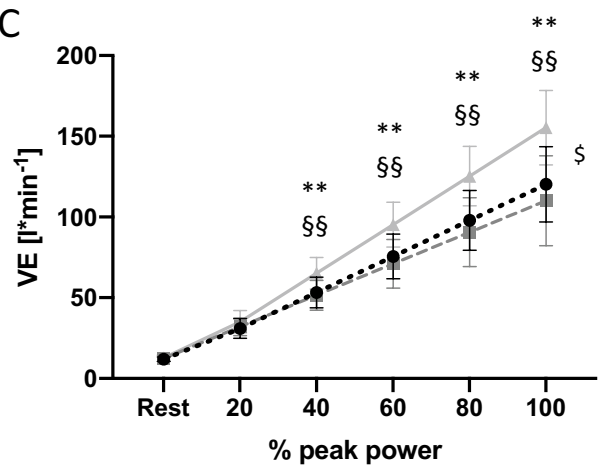

Fig. 2 Mean changes in physiological parameters throughout the incremental exercise test $(n=16)$ without a mask (NM), with a surgical mask (SM), and with FFP2-mask (FFP2). A Heart rate (HR) in beats* $\min ^{-1}(\mathrm{bpm})$. B oxygen consumption $\left(V \mathrm{O}_{2}\right)$ in $\mathrm{ml} \mathrm{kg}^{-1} \mathrm{~min}^{-1}$.
B

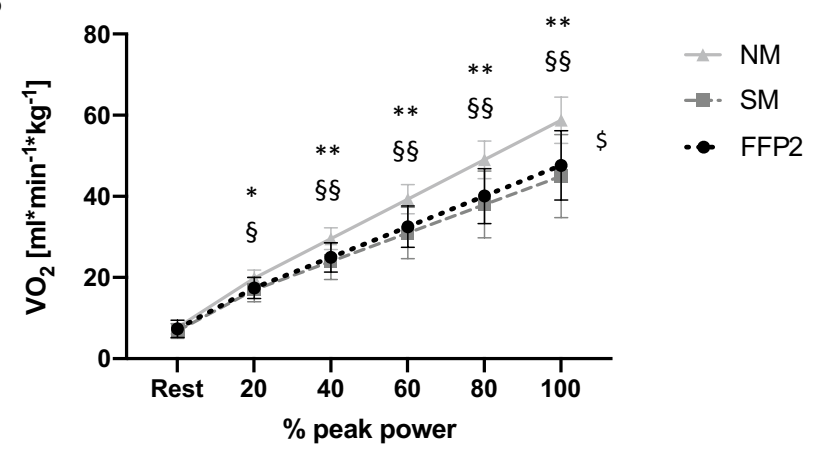

D

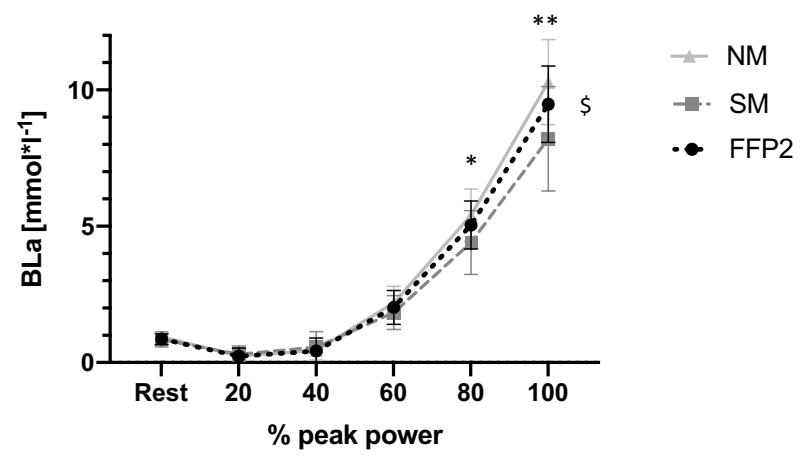

C minute ventilation (VE) in $1 \mathrm{~min}^{-1}$. D blood lactate concentration (BLa) in mmol $1^{-1}$. Error bars represent standard deviation. ${ }^{*} p<0.05$, NM vs. SM. ${ }^{* *} p<0.01, \mathrm{NM}$ vs. SM. ${ }^{{ }} p<0.05$, NM vs. FFP2. $\S^{\$} p<0.01, \mathrm{NM}$ vs. FFP2. $\%=$ time effect. $\$=$ interaction effect 
Table 1 Cardiocirculatory, respiratory and metabolic parameters at rest, during and after an incremental cycling test

\begin{tabular}{|c|c|c|c|c|c|c|c|c|}
\hline Incremental cycling test & Unit & NM & SM & FFP2 & ANOVA & NM vs. SM & NM vs. FFP2 & SM vs. FFP2 \\
\hline \multicolumn{9}{|l|}{ Rest } \\
\hline Heart rate & bpm & $74 \pm 9$ & $75 \pm 8$ & $74 \pm 11$ & 0.850 & - & - & - \\
\hline Systolic blood pressure & $\mathrm{mmHg}$ & $128 \pm 10$ & $128 \pm 12$ & $130 \pm 12$ & 0.790 & - & - & - \\
\hline Blood lactate & $\mathrm{mmol} \mathrm{l}^{-1}$ & $0.9 \pm 0.2$ & $0.8 \pm 0.2$ & $0.9 \pm 0.2$ & 0.380 & - & - & - \\
\hline $\mathrm{VO}_{2}$ & $(\mathrm{ml} / \mathrm{min}) / \mathrm{kg}$ & $7.7 \pm 1.6$ & $6.8 \pm 1.8$ & $7.2 \pm 1.7$ & 0.130 & - & - & - \\
\hline $\mathrm{VCO}_{2}$ & $(\mathrm{ml} / \mathrm{min}) / \mathrm{kg}$ & $7.3 \pm 1.3$ & $6.5 \pm 1.8$ & $6.9 \pm 2.1$ & 0.250 & - & - & - \\
\hline VE & $1 / \min$ & $12.7 \pm 2.0$ & $12.5 \pm 1.9$ & $11.9 \pm 1.3$ & 0.200 & - & - & - \\
\hline \multicolumn{9}{|l|}{ IAT } \\
\hline Performance & $\mathrm{W} / \mathrm{kg}$ & $3.7 \pm 0.5$ & $3.7 \pm 0.3$ & $3.7 \pm 0.4$ & 0.900 & - & - & - \\
\hline Heart rate & bpm & $170 \pm 13$ & $169 \pm 14$ & $169 \pm 12$ & 0.770 & - & - & - \\
\hline Blood lactate & $\mathrm{mmol} / \mathrm{l}$ & $3.0 \pm 0.4$ & $2.8 \pm 0.6$ & $2.9 \pm 0.6$ & 0.490 & - & - & - \\
\hline \multicolumn{9}{|l|}{ Exhaustion } \\
\hline Performance & $\mathrm{W} / \mathrm{kg}$ & $5.1 \pm 0.5$ & $4.8 \pm 0.4$ & $4.9 \pm 0.5$ & $<0.001$ & $<0.001$ & $<0.001$ & - \\
\hline Heart rate & bpm & $191 \pm 9$ & $189 \pm 9$ & $191 \pm 7$ & 0.290 & - & - & - \\
\hline Systolic blood pressure & $\mathrm{mmHg}$ & $227 \pm 15$ & $223 \pm 17$ & $226 \pm 16$ & 0.570 & - & - & - \\
\hline Blood lactate & & $11.9 \pm 1.8$ & $10.3 \pm 1.8$ & $11.1 \pm 1.6$ & 0.003 & 0.005 & - & - \\
\hline$V \mathrm{O}_{2}$ & $(\mathrm{ml} / \mathrm{min}) / \mathrm{kg}$ & $58.8 \pm 5.7$ & $45.0 \pm 10.2$ & $47.6 \pm 8.5$ & $<0.001$ & $<0.001$ & $<0.001$ & - \\
\hline $\mathrm{VCO}_{2}$ & $(\mathrm{ml} / \mathrm{min}) / \mathrm{kg}$ & $70.6 \pm 7.7$ & $49.7 \pm 13.8$ & $56.3 \pm 12.4$ & $<0.001$ & $<0.001$ & $<0.001$ & - \\
\hline VE & $1 / \min$ & $179.4 \pm 30.2$ & $114.7 \pm 36.3$ & $132.5 \pm 29.8$ & $<0.001$ & $<0.001$ & $<0.001$ & - \\
\hline Post-exercise & & & & & & & & - \\
\hline HRR 1 min post & bpm & $-41 \pm 10$ & $-36 \pm 12$ & $-42 \pm 13$ & 0.170 & - & - & - \\
\hline HRR 3 min post & bpm & $-69 \pm 7$ & $-72 \pm 11$ & $-74 \pm 10$ & 0.120 & - & - & - \\
\hline HRR 5 min post & bpm & $-78 \pm 9$ & $-81 \pm 11$ & $-81 \pm 10$ & 0.150 & - & - & - \\
\hline
\end{tabular}

Significant results are presented in bold. $V \mathrm{O}_{2}$ oxygen uptake, $V \mathrm{CO}_{2}$ carbon dioxide production, $V E$ minute ventilation, IAT individual anaerobic threshold, HRR heart rate recovery, $b p m$ beats per minute, $W$ Watt

16 subjects $(69 \%)$ with SM. With FFP2, none of the subjects reported mask deformation and only 2 of 16 subjects (13\%) complained of moisture retention within the mask at higher intensities.

\section{Discussion}

This randomized cross-over study was the first to investigate the effects of medical face masks on performance in welltrained athletes. Firstly, wearing a face mask was associated with a significant reduction (almost 6\%) in maximum power output (more pronounced for SM than FFP2), but not associated with a change in submaximal performance (workload at IAT). Secondly, during the incremental cycling tests, $V_{2}$ and VE were reduced with both masks and BLa with SM. Thirdly, no difference in RPE was observed between conditions during exercise, however, subjects reported a considerable rate of abrupt exercise cessation due to acute dyspnea associated with suction of the wet and deformed mask (SM), or to a lesser extent, discomfort at higher intensities from moisture retention alone (FFP2).

\section{Performance}

Our results are supported by a recent study in healthy volunteers showing that wearing an FFP2 mask (and to a lesser extent SM) was associated with reduced $P_{\max }, V \mathrm{O}_{2}$ and $\mathrm{VE}$ during an incremental exercise test [9]. As in the present study, the underlying physiological effect for performance impairment appears to be pulmonary, due to reduced VE indicating increased breathing resistance of the mask, which has already been shown for respiratory protective devices, externally added breathing resistance or N95 respirators [19-21]. Moreover, a recent study found a two-fold higher airway resistance with SM compared to NM [10]. However, two previous studies found no detrimental effects on maximum cycling performance [7,8]. When comparing SM, N95 respirators, and NM, cycling time to exhaustion did not differ in sixteen untrained males, and no symptoms emerged despite a mild increase in end-tidal carbon dioxide (re-breathing of the expired air) with both masks [7]. Furthermore, there was no difference in performance, tissue oxygenation index or arterial oxygen saturation between SM, cloth masks or NM in fourteen untrained volunteers [8]. In these studies, however, the detrimental effect of (surgical) 
masks on performance (soaking and deformation of the mask associated with acute dyspnea) was not present as observed in our study. In contrast to our study, the study population consisted of untrained individuals or recreational athletes (non-cyclists) who typically do not reach physical exhaustion (early test termination due to leg fatigue, poor motivation or decreased pain tolerance) compared with well-trained cyclists [22, 23]. Therefore, SM soaking and deformation probably did not occur to the same extent as in the endurance cyclists studied herein, as moisture retention increases with exercise intensity (proportion of oral breathing) and sweating [24, 25]. In addition, athletes achieve higher peak minute ventilation due to their higher cardiopulmonary exercise capacity compared to untrained individuals, which may explain the increased moisture retention. The adverse effect on performance with SM (and to a lesser extent with FFP2) in our study could at least partly be due to increased breathing resistance, which has been shown to be associated with moisture retention [26].

With FFP2, our subjects reported no mask deformation or suction associated with acute dyspnea, most likely because this mask type is more rigid than SM [6]. In our study, the performance impairment with both masks occurred acutely and to some extent unexpectedly, which is supported by the unchanged RPE between all conditions. In this context, an equally high RPE value with absolutely lower performance with SM and FFP2 corresponds to a relative RPE increase. The lower BLa concentrations at the highest intensity with FFP2 and SM, as observed recently [9], appear to be a reflection of early exercise cessation rather than a consequence of wearing a mask.

\section{Physiological response}

This study was the first to estimate the effects of wearing a face mask on submaximal performance in athletes, more specifically at the IAT, an intensity marker of metabolic stress commonly used for training prescriptions in endurance sports $[11,12]$. Since IAT did not differ between NM, SM, and FFP2, endurance training at or below IAT does not appear to have any detrimental effects on athletes when wearing a mask. Similarly, a study on steady-state exercise in non-athletes found unchanged endurance performance between SM and NM [10]. Nevertheless, in contrast to previous studies with face masks, which focused on metabolic response during exercise at a single time point $[7,10]$, we analyzed the submaximal performance using the BLa performance curve. Thus, it was possible to assess the metabolic response at different submaximal intensities (beyond the IAT), such as the lowered BLa at $80 \%$ peak power output with SM. The latter is likely associated with a decrease in performance as observed at maximum performance. In contrast, BLa at $20 \%, 40 \%$ or $60 \%$ peak power output (common training intensities in leisure sport) did not differ between NM and SM suggesting no detrimental effect on performance. Consistent with previous studies, we observed no changes in heart rate between conditions during exhaustive exercise [7-9]. In contrast, a significant increase in heart rate was observed during steady-state exercise (30-min constant exercise test) with SM, which was interpreted as a result of increased work of breathing [10]. During exhaustive exercise, only one study in healthy individuals reported an increased heart rate with SM compared with NM during a simulated hike at a comfortable pace, which was thought to be a physiological response to restricted ventilation [27]. However, limitations in statistical testing with the use of repeated measures $t$-test may challenge the external validity of this study. In contrast, heart rate did not differ in patients with established cardiovascular disease wearing an FFP1 mask during a 2-h walk compared with NM [28]. Patients with severe lung damage, such as chronic obstructive pulmonary disease, exhibit a higher heart rate after exercise (6-min walk test) when wearing an N95 respirator compared to without, which could be interpreted as a compensatory mechanism for impaired lung capacity [29]. Since a gradual decrease in diastolic blood pressure with exercise is considered normal in healthy individuals and adds no prognostic value of stress tests [30, 31], our focus was on systolic blood pressure. In line with previous studies, masks were not associated with changes in systolic blood pressure at exhaustion $[7,9]$.

\section{Limitations}

The study population consisted of well-trained male endurance athletes, and thus the results cannot be generalized to females, untrained persons or patients with other diseases. Exercise testing was conducted as a short exhaustive incremental cycling test, which limits the transferability to long-term endurance exercise. Although this was the first, randomized, cross-over study to examine the effects of face masks on athlete performance, larger sample size and investigations in different sports may be needed to substantiate our findings. Due to the experimental setup, the external validity of surgical mask testing (significant leakage to the nose and ears) was limited by the fitting of the spirometry mask, which completely sealed the SM. It cannot be excluded that the sealing of the SM contributed to moisture retention within the mask, although this is influenced by several other factors such as training intensity or sweating $[24,25]$. Therefore, the transferability of the investigational set-up (spirometry mask + face mask) to daily training conditions or competition of athletes remains limited. Nevertheless, dyspnea and suction of the deformed and wet SM is a phenomenon, which could be also relevant for non-athletes 
or patients in the presence of increasing ambient humidity and temperature (kept constant in our study).

\section{Conclusion}

Exhaustive exercise with both SM and FFP2 was associated with reduced maximum performance in athletes. Although the athletes did not perceive increased exertion at higher intensities with mask, an unexpected abrupt exercise cessation occurred, which was described as acute dyspnea due to suction of the deformed and soaked mask (more likely to occur with SM but not with the more stable FFP2). Submaximal performance at IAT did not differ between masks and NM. For sports activities where masks are mandatory to actively contain transmission respiratory viruses, such as outdoor sports in crowded areas (i.e. city parks) or training in sports centers and gyms including participation in indoor contact sports, anaerobic intensities should be approached with caution and an FFP2 mask, which appears to be better tolerated, should be preferred over an SM.

Funding Open Access funding enabled and organized by Projekt DEAL. The authors received no financial support for the research, authorship, and/or publication of this article.

\section{Declarations}

Conflict of interest On behalf of all authors, the corresponding author states that there is no conflict of interest.

Ethical approval The study was approved by the local ethics committee (Ärztekammer des Saarlandes, Saarbrücken, Germany; approval number: 199/20).

Open Access This article is licensed under a Creative Commons Attribution 4.0 International License, which permits use, sharing, adaptation, distribution and reproduction in any medium or format, as long as you give appropriate credit to the original author(s) and the source, provide a link to the Creative Commons licence, and indicate if changes were made. The images or other third party material in this article are included in the article's Creative Commons licence, unless indicated otherwise in a credit line to the material. If material is not included in the article's Creative Commons licence and your intended use is not permitted by statutory regulation or exceeds the permitted use, you will need to obtain permission directly from the copyright holder. To view a copy of this licence, visit http://creativecommons.org/licenses/by/4.0/.

\section{References}

1. Brooks JT, Butler JC, Redfield RR (2020) Universal masking to prevent SARS-CoV-2 transmission-the time is now. JAMA. https://doi.org/10.1001/jama.2020.13107

2. Ueki H, Furusawa Y, Iwatsuki-Horimoto K et al (2020) Effectiveness of face masks in preventing airborne transmission of SARSCoV-2. mSphere. https://doi.org/10.1128/mSphere.00637-20
3. Rader B, White LF, Burns MR et al (2021) Mask-wearing and control of SARS-CoV-2 transmission in the USA: a cross-sectional study. Lancet Digit Health. https://doi.org/10.1016/s25897500(20)30293-4

4. Centers for Disease Control and Prevention (2021) Public Health Guidance for Community-Related Exposure. https://www.cdc. gov/coronavirus/2019-ncov/php/public-health-recommendations. html

5. World Health Organization (2020) Mask use in the context of COVID-19. Interim guidance. https://www.who.int/publicatio ns/i/item/advice-on-the-use-of-masks-in-the-community-during-home-care-and-in-healthcare-settings-in-the-context-of-thenovel-coronavirus-(2019-ncov)-outbreak

6. Tcharkhtchi A, Abbasnezhad N, Zarbini Seydani M, Zirak N, Farzaneh S, Shirinbayan M (2021) An overview of filtration efficiency through the masks: mechanisms of the aerosols penetration. Bioact Mater 6(1):106-122. https://doi.org/10.1016/j. bioactmat.2020.08.002

7. Epstein D, Korytny A, Isenberg Y, Marcusohn E, Zukermann R, Bishop B, Minha S, Raz A, Miller A (2021) Return to training in the COVID-19 era: the physiological effects of face masks during exercise. Scand J Med Sci Sports 31(1):70-75. https:// doi.org/10.1111/sms.13832

8. Shaw K, Butcher S, Ko J, Zello GA, Chilibeck PD (2020) Wearing of cloth or disposable surgical face masks has no effect on vigorous exercise performance in healthy individuals. Int $\mathrm{J}$ Environ Res Public Health. https://doi.org/10.3390/ijerph1721 8110

9. Fikenzer S, Uhe T, Lavall D, Rudolph U, Falz R, Busse M, Hepp P, Laufs U (2020) Effects of surgical and FFP2/N95 face masks on cardiopulmonary exercise capacity. Clin Res Cardiol 109(12):1522-1530. https://doi.org/10.1007/s00392-020-01704-y

10. Lässing J, Falz R, Pökel C, Fikenzer S, Laufs U, Schulze A, Hölldobler N, Rüdrich P, Busse M (2020) Effects of surgical face masks on cardiopulmonary parameters during steady state exercise. Sci Rep 10(1):22363. https://doi.org/10.1038/ s41598-020-78643-1

11. Faude O, Kindermann W, Meyer T (2009) Lactate threshold concepts: how valid are they? Sports Med 39(6):469-490. https://doi. org/10.2165/00007256-200939060-00003

12. Mann T, Lamberts RP, Lambert MI (2013) Methods of prescribing relative exercise intensity: physiological and practical considerations. Sports Med 43(7):613-625. https://doi.org/10.1007/ s40279-013-0045-x

13. De Pauw K, Roelands B, Cheung SS, de Geus B, Rietjens G, Meeusen R (2013) Guidelines to classify subject groups in sportscience research. Int J Sports Physiol Perform 8(2):111-122. https://doi.org/10.1123/ijspp.8.2.111

14. Borg G (1998) Borg's perceived exertion and pain scales. Human kinetics

15. Stegmann H, Kindermann W, Schnabel A (1981) Lactate kinetics and individual anaerobic threshold. Int J Sports Med 2(3):160 165. https://doi.org/10.1055/s-2008-1034604

16. Löllgen H, Leyk D (2018) Exercise testing in sports medicine. Dtsch Arztebl Int 115(24):409-416. https://doi.org/10.3238/arzte bl.2018.0409

17. Tanaka H, Monahan KD, Seals DR (2001) Age-predicted maximal heart rate revisited. J Am Coll Cardiol 37(1):153-156. https://doi. org/10.1016/s0735-1097(00)01054-8

18. Cohen J (1988) Statistical power analysis for the behavioral sciences, 2nd edn. Lawrence Erlbaum Associates, Hillsdale, p 567

19. Louhevaara VA (1984) Physiological effects associated with the use of respiratory protective devices. A review. Scand J Work Environ Health 10(5):275-281. https://doi.org/10.5271/sjweh. 2327 
20. Melissant CF, Lammers JW, Demedts M (1998) Relationship between external resistances, lung function changes and maximal exercise capacity. Eur Respir J 11(6):1369-1375. https://doi.org/ 10.1183/09031936.98.11061369

21. Lee HP, de Wang Y (2011) Objective assessment of increase in breathing resistance of N95 respirators on human subjects. Ann Occup Hyg 55(8):917-921. https://doi.org/10.1093/annhyg/ mer065

22. Fletcher GF, Ades PA, Kligfield P, Arena R, Balady GJ, Bittner VA, Coke LA, Fleg JL, Forman DE, Gerber TC, Gulati M, Madan K, Rhodes J, Thompson PD, Williams MA (2013) Exercise standards for testing and training: a scientific statement from the American Heart Association. Circulation 128(8):873-934. https://doi. org/10.1161/CIR.0b013e31829b5b44

23. Smirmaul BP, Dantas JL, Fontes EB, Altimari LR, Okano AH, Moraes AC (2010) Comparison of electromyography fatigue threshold in lower limb muscles in trained cyclists and untrained non-cyclists. Electromyogr Clin Neurophysiol 50(3-4):149-154

24. Roberge RJ, Kim JH, Coca A (2012) Protective facemask impact on human thermoregulation: an overview. Ann Occup Hyg 56(1):102-112. https://doi.org/10.1093/annhyg/mer069

25. Purushothaman PK, Priyangha E, Vaidhyswaran R (2020) Effects of prolonged use of facemask on healthcare workers in tertiary care hospital during COVID-19 pandemic. Indian J Otolaryngol Head Neck Surg. https://doi.org/10.1007/s12070-020-02124-0

26. Rebmann T, Carrico R, Wang J (2013) Physiologic and other effects and compliance with long-term respirator use among medical intensive care unit nurses. Am J Infect Control 41(12):1218-1223. https://doi.org/10.1016/j.ajic.2013.02.017

27. Wong AY, Ling SK, Louie LH, Law GY, So RC, Lee DC, Yau FC, Yung PS (2020) Impact of the COVID-19 pandemic on sports and exercise. Asia Pac J Sports Med Arthrosc Rehabil Technol 22:39-44. https://doi.org/10.1016/j.asmart.2020.07.006

28. Langrish JP, Li X, Wang S, Lee MM, Barnes GD, Miller MR, Cassee FR, Boon NA, Donaldson K, Li J, Li L, Mills NL, Newby DE, Jiang L (2012) Reducing personal exposure to particulate air pollution improves cardiovascular health in patients with coronary heart disease. Environ Health Perspect 120(3):367-372. https:// doi.org/10.1289/ehp.1103898

29. Kyung SY, Kim Y, Hwang H, Park JW, Jeong SH (2020) Risks of N95 face mask use in subjects with COPD. Respir Care 65(5):658-664. https://doi.org/10.4187/respcare.06713

30. Sydó N, Sydó T, Gonzalez Carta KA, Hussain N, Merkely B, Murphy JG, Squires RW, Lopez-Jimenez F, Allison TG (2018) Significance of an increase in diastolic blood pressure during a stress test in terms of comorbidities and long-term total and CV mortality. Am J Hypertens 31(9):976-980. https://doi.org/10. 1093/ajh/hpy080

31. Wolthuis RA, Froelicher VF Jr, Fischer J, Triebwasser JH (1977) The response of healthy men to treadmill exercise. Circulation 55(1):153-157. https://doi.org/10.1161/01.cir.55.1.153 